\title{
Effective Response of Methotrexate for Recurrent Idiopathic Hypertrophic Spinal Pachymeningitis
}

\author{
Tae Joon Park ${ }^{1}$, Won Deok Seo ${ }^{2}$, Sang Young Kim¹, Jae Hoon Cho', \\ Dae Hyun Kim ${ }^{1}$, Ki Hong Kim ${ }^{1}$

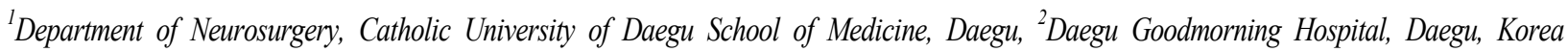

\begin{abstract}
Idiopathic hypertrophic spinal pachymeningitis (IHSP) is a chronic progressive and diffuse inflammatory fibrosis of the spinal dura mater. Though treatment of IHSP is surgical decompression with steroid therapy, treatment for recurrent IHSP is controversial. Our patient was diagnosed with IHSP based on magnetic resonance imaging (MRI) and underwent laminectomy for decompression following steroid pulse therapy. Despite maintenance of steroid therapy, the patient experienced 3 recurrences. As an alternative immunosuppressant medication, methotrexate was introduced with low-dose steroid. Fortunately, the symptom was resolved, and a decrease of dura thickening was revealed on MRI. We present the case and suggest that methotrexate might be an effective treatment modality for recurrent IHSP.
\end{abstract}

Key Words: Pachymeningitis $\cdot$ Steroid $\cdot$ Methotrexate

\section{INTRODUCTION}

Idiopathic hypertrophic spinal pachymeningitis (IHSP) is a chronic progressive and diffuse inflammatory fibrosis of the spinal dura mater. This rare disorder typically occurs intracranially. The related etiologies are autoimmune disease, tuberculosis, and sarcoidosis. Differential diagnosis is a neoplastic condition such as meningioma and lymphoma ${ }^{10-12,18)}$. The disease entity of IHSP was first reported by Charcot and Joffroy ${ }^{5}$ in 1869 , and Naffziger et al. ${ }^{14)}$ described a case of idiopathic hypertrophic cranial pachymeningitis (IHCP). The clinical manifestation is due to compression of the spinal cord and nerve root and includes myelopathy, radiculopathy, and back pain. Though there are insufficient reports of treatment and longterm outcomes of IHSP, the acceptable treatment of IHSP is surgical resection and decompression with steroid therapy. However, the management of recurrent of IHSP has not yet been established.

We present a case of recurrent IHSP treated with methotrexate and demonstrating a good outcome and suggest that methotrexate might be an effective treatment modality.

- Received: October 20, 2016 • Revised: December 22, 2016

- Accepted: December 23, 2016

Corresponding Author: Ki Hong Kim

Department of Neurosurgery, Catholic University of Daegu School of Medicine, 33 Duryugongwon-ro 17-gil, Nam-gu, Daegu 42472, Korea Tel: +82-53-650-4625, Fax: +82-53-650-4932

E-mail: gneuros@cu.ac.kr

$\otimes$ This is an open access article distributed under the terms of the Creative Commons Attribution Non-Commercial License (http://creativecommons.org/licenses/by-nc/4.0/) which permits unrestricted non-commercial use, distribution, and reproduction in any medium, provided the original work is properly cited.

\section{CASE REPORT}

A 51-year-old woman was admitted to our institution with a complaint of progressive lower limb weakness. Fifteen days prior to admission, the patient had experienced upper back pain and paresthesia of both lower limbs. The patient had no past or family history and no recent history of traumatic injury. On physical examination, the patient had weakness of both lower limbs of grade 4/5 and hyperesthesia below the T10 level. Deep tendon reflexes and urination were normal. The patient had no fever. On laboratory tests, white blood cell count $(4,200 / \mu \mathrm{L})$ was normal, although erythrocyte sedimentation rate $(120 \mathrm{~mm} / \mathrm{hr}$ ) (normal value, $0-20 \mathrm{~mm} / \mathrm{hr}$ ) and serum C-reactive protein level $(15.7 \mathrm{mg} / \mathrm{L}$ ) (normal value, $0-5 \mathrm{mg} / \mathrm{L}$ ) were increased. No abnormal bony structure and calcification reveal on sagittal computerized tomographic image. Magnetic resonance imaging (MRI) showed ventral and dorsal dura thickening between $\mathrm{T} 2$ and $\mathrm{T} 9$, with spinal cord compression from T3 to T5 (Fig. 1). The thickened dura revealed low signal intensity on T2- and T1-weighted images and homogenous enhancement with gadolinium.

We performed decompressive laminectomy on T3 to T5. In the operative field, granulomatous tissue was noted mainly in the ventral area mainly but also in the dorsal area. The tissue was strongly adhered to the dura mater and epidural fat. Partial resection of the granulomatous tissue with dissection of the adjacent dura mater was performed.

Histopathologic examination showed patchy infiltration of chronic inflammatory lymphocytes and plasma cells (Fig. 2). Lymphoma was excluded by confirmation of mixed type lymphocytes on immunohistochemistry. Other granulomatous dis- 

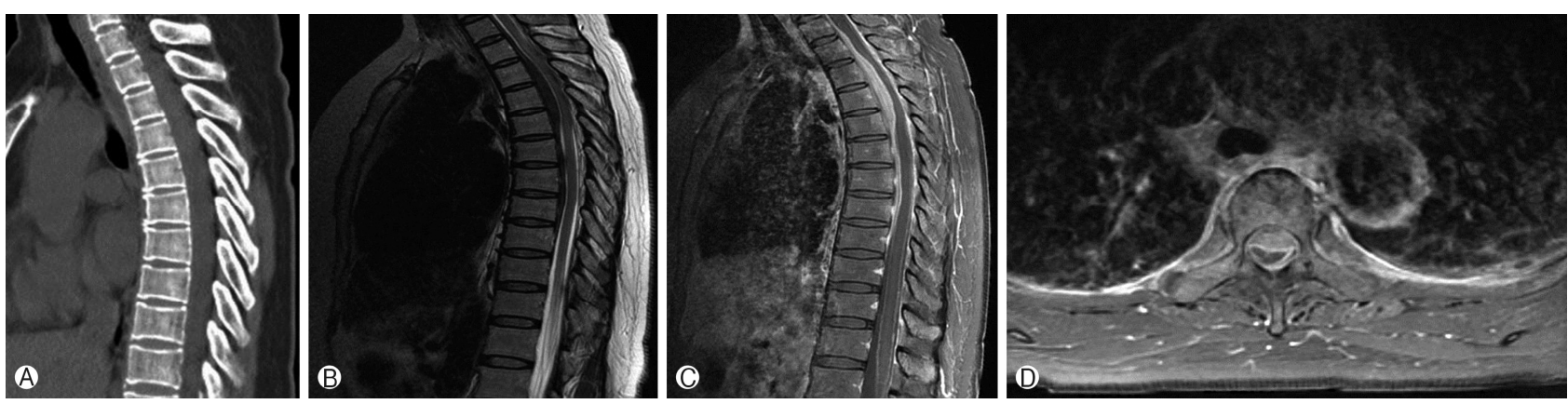

Fig. 1. (A) No abnormal finding of bony structure reveals on sagittal computed tomographic image. (B) Sagittal T2 image shows low signal area between T2 and T9. Sagittal (C) and axial (D) T1-weighted images with gadolinium reveal ventral and dorsal dura thickening between T2 and T9 with spinal cord compression from T3 to T5.

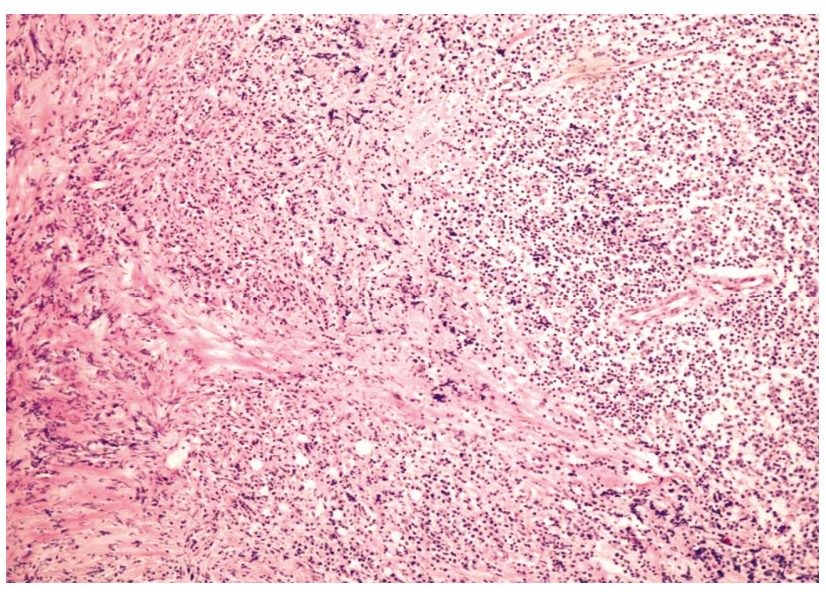

Fig. 2. Photomicrographs of surgical specimen shows patchy infiltration of chronic inflammatory lymphocytes and plasma cells $(\mathrm{H} \& \mathrm{E}, \times 100)$.

eases, such as sarcoidosis and Wegner's granulomatosis, also were excluded. Stains for tuberculosis and fungal infection were negative. The final histopathological diagnosis was IHSP.

Postoperatively, the patient received steroid pulse therapy and achieved symptom improvement. MRI performed 15 days after the operation revealed a decompressed cord with laminectomy and a decrease in the thickness of the ventral dura mater from T3 to T5 (Fig. 3).

After 8 months, the patient was readmitted to our institution with back pain and lower limb weakness. MRI showed a decreased in ventral dura mater thickening from T3 to T5 but diffuse dura mater thickening from T1 to T12. The patient received a second round of steroid pulse therapy, after which she experienced 2 more recurrences and waxing and waning of symptoms. Finally, the patient demonstrated a refractory period without improvement of symptoms after steroid therapy. Therefore, we decided oral methotrexate therapy despite weak evidence in a review of the literature. We prescribed combination therapy with methotrexate $(12.5 \mathrm{mg})$ and lowdose steroid $(5 \mathrm{mg})$. After this treatment, the patient experienced no relapse of symptoms for 1 year and demonstrated a decrease in diffuse dura thickening on MRI (Fig. 4).

\section{DISCUSSION}

IHSP is a very rare disease entity that is characterized by thickening of the dura mater due to chronic inflammation and fibrosis. The pathogenesis of IHSP is unknown; however, several diseases shown an association with IHSP, including trauma, metabolic disorder, autoimmune disease, and sarcoidosis. Also, infectious diseases such as neurosyphilis, tuberculosis, human T-lymphotrophic virus-1 (HTLV-1), meningococcal meningitis, granulomatous sinusitis, and fungal infection might be associated $^{10-12,18)}$. Exclusion of neoplasms such as meningioma, lymphoma, and metastatic carcinoma, and degenerative disease such as ossification of the posterior longitudinal ligament is needed for diagnosis of IHSP. In our case, no associated diseases were identified.

\section{Diagnosis}

Diagnosis of IHSP is made based on histopathologic findings through an open biopsy. IHSP is histopathologically characterized by chronic nonspecific and granulomatous inflammation of the dura ${ }^{15}$. The infiltration of inflammatory cells such as plasma cells, lymphocytes, giant cells, polymorphonuclear cells, and eosinophils has been identified ${ }^{1,7}$. Radiological diagnosis of MRI is obtained based on low signal intensity of a dura-based mass with encasement of some part of the central nervous system on T2- and T1-weighted images and greater enhancement of the peripheral zone than the central zone. In our case, a mass was observed as typically thickened dura mater with homogenous enhancement but not peripheral zone enhancement.

\section{Clinical Manifestation}

The clinical presentation of IHSP is dependent on lesion location and size. The early stage manifestation of IHSP is localized back pain, which can progress to lower limb weakness 

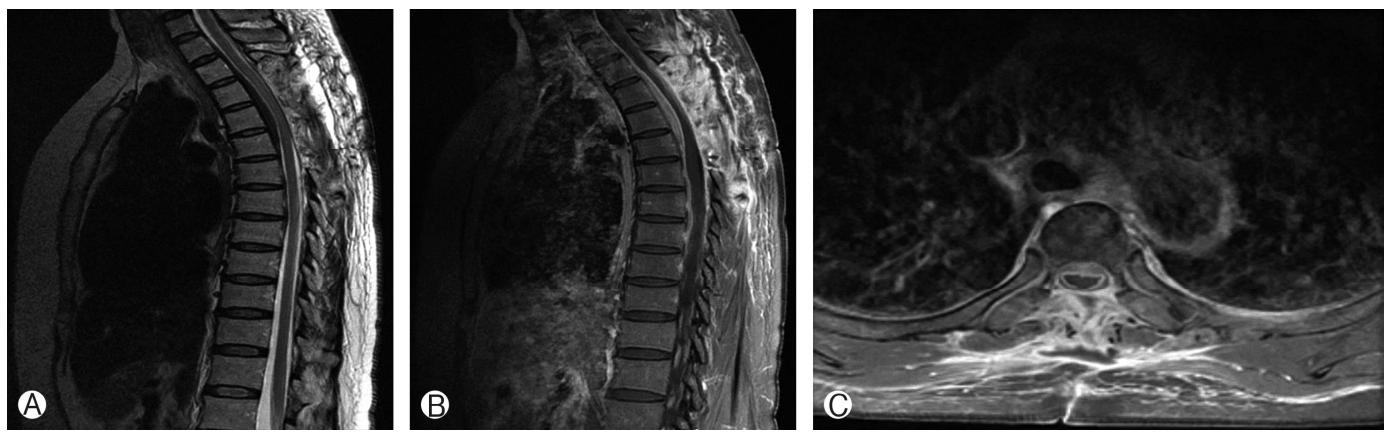

Fig. 3. Postoperative T2-sagittal image (A) and T1-sagittal (B) and -axial (C) images with gadolinium show a decompressed cord with laminectomy and a decrease in the thickness of the ventral dura mater from T3 to T5.
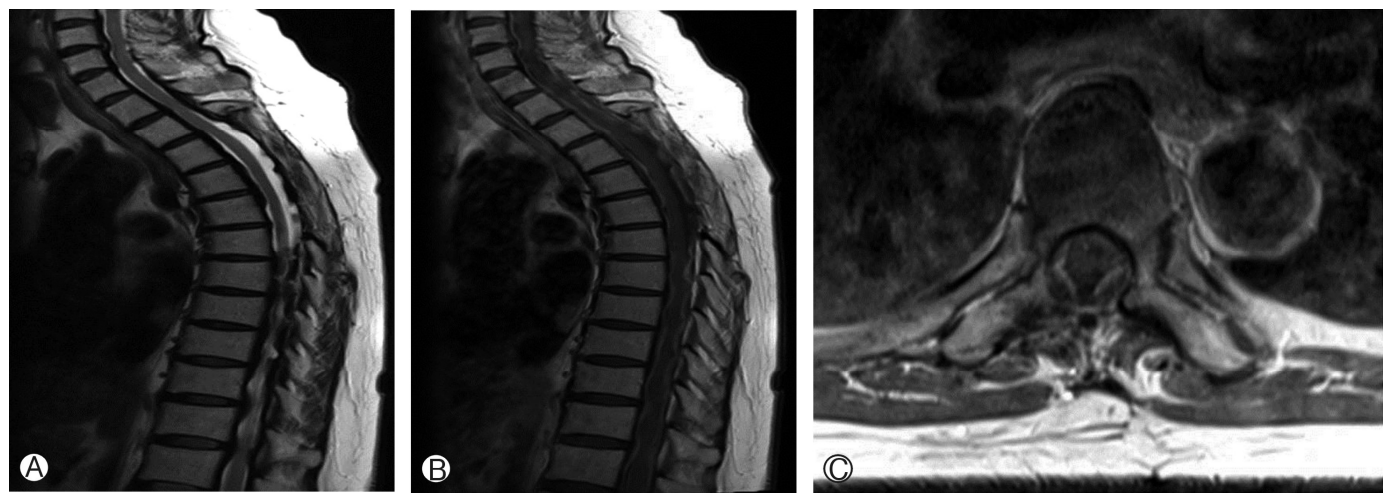

Fig. 4. T2-sagittal image (A) and T1-sagittal (B) and -axial (C) images with gadolinium after methotrexate therapy demonstrate a decrease in diffuse dura thickening.

and paresthesia. Charcot was the first to report the progressive stage-based symptoms ${ }^{5}$. In the first stage, IHSP is characterized by progressing radicular symptoms. The second stage involves muscle weakness and atrophy, followed by the lower limb paresthesia and bladder and bowel dysfunctions that characterize the third stage.

\section{Management}

The optimal management of IHSP is controversial. Surgical decompression by laminectomy and lesion excision are considered to relieve symptoms and obtain pathological diagno$\operatorname{sis}^{4,6,14)}$. Complete lesion resection can be difficult due to the typical diffusivity and long axis of the lesion. Recently, additional treatment after surgical decompression was reported. Steroid therapy is an effective medical treatment option to control symptoms by reducing dura thickness. Also, postoperative radiotherapy and immunosuppressive therapies such as azathioprine, cyclophosphamide, and methotrexate have been reported as alternative medical treatment options ${ }^{3,4,6)}$. In our case, after laminectomy and excision biopsy following steroid pulse therapy, the patient achieved improvement in symptoms. Oral prednisolone (15 mg daily) was used as a maintenance steroid therapy, and the patient underwent an uneventful course for 8 months.

\section{Recurrence and Treatment}

Reports of recurrent IHSP are very limited because of the small number of affected patients and the short-term follow-up period. Ito et al. ${ }^{9)}$ reported 2 cases of recurrent IHSP with review of the literature. They reviewed a total of 96 patients, 11 of whom experienced recurrence (11\%). In addition, they concluded that recurrence was not caused by residual lesion, but by active inflammation of the dura mater present before surgery. However, the mean follow-up period of reviewed patients was short (1.3 years; range, 1 week -4 years). Recently, Tsutsui et al. $^{20)}$ has reported a long-term follow-up of 5 years of IHSP with a high recurrence rate and a review of the literature. Disease progression has been reported to be related to increased cerebro-spinal fluid protein and cells ${ }^{16}$. Another study has suggested that recurrence is related to immuno-suppressant therapy such as steroid ${ }^{17)}$.

Treatment for recurrent IHSP has not yet been established. Generally, repeated surgery or combined therapy with steroid is performed. Alternative medical treatments have been attempted in many institutions, including methotrexate, though no conclusive evidence has been reported. Methotrexate is an 
antimetabolite and antifolate drug that acts by inhibiting the metabolism of folic acid via dihydrofolate reductase and is used in treatment of cancer, autoimmune diseases, and ectopic pregnancy. Methotrexate could be used to substitute for steroid due to side effects, drug dependence, and absence of response to it, or to reduce steroid dose through combination therapy. Bosman has reported that patients with idiopathic hypertrophic pachymeningitis due to a cranial lesion can be treated using a combination therapy with methotrexate when they are refractory to glucocorticoid therapy or present with serious complications of long-term steroid therapy ${ }^{3)}$. In our review of the literature, 12 patients with idiopathic hypertrophic cranial pachymeningitis was treated initially with methotrexate only or combined therapy with steroid ${ }^{2,3,7,8,10,13,19)}$. However, there is no report of methotrexate in the management of IHSP. There was one report of methotrexate for recurrent idiopathic hypertrophic pachymeningitis of a cranial lesion ${ }^{8)}$. The optimal treatment dose, duration, and maintenance dose could not be determined; however, all patients had a good outcome and demonstrated no complications related to methotrexate. Our case of recurrent IHSP refractory to steroid is the first trial of methotrexate and presented a good outcome without complications.

\section{CONCLUSION}

The current treatment for IHSP is surgical decompression and lesion resection with steroid therapy. In recurrent IHSP, reoperation and repeat steroid therapy has been performed, although other medical treatments have been required due to the complications of long-term and high-dose steroid therapy. Methotrexate might be an effective medical treatment option. However, a well-designed randomized study with a large number of patients is needed to demonstrate the efficacy of methotrexate.

\section{CONFLCT OF INTEREST}

No potential conflict of interest relevant to this article was reported.

\section{REFERENCES}

1. Ashkenazi E, Constantini S, Pappo O, Gomori M, AverbuchHeller L, Umansky F: Hypertrophic spinal pachymeningitis: report of two cases and review of the literature. Neurosurgery 28:730-732, 1991

2. Auboire L, Boutemy J, Constans JM, Le Gallou T, Busson P, Bienvenu B: Idiopathic hypertrophic pachymeningitis presenting with occipital neuralgia. Afr Health Sci 15:302-306, 2015

3. Bosman T, Simonin C, Launay D, Caron S, Destée A, Defebvre L: Idiopathic hypertrophic cranial pachymeningitis treated by ral methotrexate: a case report and review of literature. Rheu- matol Int 28:713-718, 2008

4. Bucy PC, Freeman LW: Hypertrophic spinal pachymeningitis with special reference to appropriate surgical treatment. J Neurosurg 9:564-578, 1952

5. Charcot JM, Joffroy A: Deux cas d'atrophie musculaire progressive avec lesions de la substance grise et des faisceaux anterolateraux dela moelle epiniere. Arch Physiol Norm Pathol 2:354367, 744-760, 1869

6. Dumont AS, Clark AW, Sevick RJ, Myles ST: Idiopathic hypertrophic pachymeningitis: a report of two patients and review of the literature. Can J Neurol Sci 27:333-340, 2000

7. Hamilton SR, Smith $\mathrm{CH}$, Lessell S: Idiopathic hypertrophic cranial pachymeningitis. J Clin Neuroophthalmol 13:127-134, 1993

8. Im SH, Cho KT, Seo HS, Choi JS: Idiopathic hypertrophic cranial pachymeningitis presenting with headache. Headache 48: 1232-1235, 2008

9. Ito Z, Osawa Y, Matsuyama Y, Aoki T, Harada A, Ishiguro $\mathrm{N}$ : Recurrence of hypertrophic spinal pachymeningitis. Report of two cases and review of the literature. J Neurosurg Spine 4: 509-513, 2006

10. Kupersmith MJ, Martin V, Heller G, Shah A, Mitnick HJ: Idiopathic hypertrophic pachymeningitis. Neurology 62:686-694, 2004

11. Lee YC, Chueng YC, Hsu SW, Lui CC: Idiopathic hypertrophic cranial pachymeningitis: case report with 7 years of imaging follow-up. AJNR Am J Neuroradiol 24:119-123, 2003

12. Martin N, Masson C, Henin D, Mompoint D, Marsault C, Nahum H: Hypertrophic cranial pachymeningitis: assessment with CT and MR imaging. AJNR Am J Neuroradiol 10:477-484, 1989

13. Mathew RG, Hogarth KM, Coombes A: Idiopathic hypertrophic cranial pachymeningitis presenting as acute painless visual loss. Int Ophthalmol 32:195-197, 2012

14. Naffziger HC, Stern WE: Chronic pachymeningitis; report of a case and review of the literature. Arch Neurol Psychiatry 62: 383-411, 1949

15. Nishizaki T, Iwamoto F, Uesugi S, Akimura T, Yamashita K, Ito $\mathrm{H}$ : Idiopathic cranial pachymeningoencephalitis focally affecting the parietal dura mater and adjacent brain parenchyma: case report. Neurosurgery 40:840-843, 1997

16. Qin LX, Wang CY, Hu ZP, Zeng LW, Tan LM, Zhang HN: Idiopathic hypertrophic spinal pachymeningitis: a case report and review of literature. Eur Spine J 24 Suppl 4:S636-643, 2015

17. Ranasinghe MG, Zalatimo O, Rizk E, Specht CS, Reiter GT, Harbaugh RE, et al: Idiopathic hypertrophic spinal pachymeningitis. J Neurosurg Spine 15:195-201, 2011

18. Riku S, Kato S: Idiopathic hypertrophic pachymeningitis. Neuropathology 23:335-344, 2003

19. Ruiz-Sandoval JL, Bernard-Medina G, Ramos-Gómez EJ, Romero-Vargas S, Gutiérrez-Ureña S, González-Cornejo S, et al: Idiopathic hypertrophic cranial pachymeningitis successfully treated with weekly subcutaneous methotrexate. Acta Neurochir (Wien) 148:1011-1014, 2006

20. Tsutsui M, Yasuda T, Kanamori M, Hori T, Kimura T: Longterm outcome of idiopathic hypertrophic thoracic pachymeningitis. Eur Spine J 21 Suppl 4:S404-407, 2012 